\title{
Control Demonstration of Multiple Doubly-Fed Induction Motors for Hybrid Electric Propulsion
}

\author{
David J. Sadey ${ }^{1}$ \\ NASA Glenn Research Center, Cleveland, OH, 44135 \\ Marc Bodson ${ }^{2}$ \\ University of Utah, Salt Lake City, Utah, 84112 \\ Jeffrey T. Csank ${ }^{3}$, Keith R. Hunker ${ }^{4}$, Casey J. Theman ${ }^{5}$, and Linda M. Taylor ${ }^{6}$ \\ NASA Glenn Research Center, Cleveland, OH, 44135
}

\begin{abstract}
The Convergent Aeronautics Solutions (CAS) High Voltage-Hybrid Electric Propulsion (HVHEP) task was formulated to support the move into future hybrid-electric aircraft. The goal of this project is to develop a new AC power architecture to support the needs of higher efficiency and lower emissions. This proposed architecture will adopt the use of the doublyfed induction machine (DFIM) for propulsor drive motor application. DFIMs are attractive for several reasons, including but not limited to the ability to self-start, ability to operate suband super-synchronously, and requiring power converters rated at a fraction of what would be required in a corresponding DC system, depending on the required range of operation. The focus of this paper is based specifically on the presentation and analysis of a novel strategy which allows for independent operation of each of the aforementioned doubly-fed induction motors. This strategy includes synchronization, soft-start, and closed loop speed control of each motor as a means of controlling output thrust; be it concurrently or differentially. The demonstration of this strategy has recently been proven out on a low power test bed using fractional horsepower machines. Simulation and hardware test results are presented in the paper.
\end{abstract}

\begin{tabular}{l} 
COTS \\
DFIM \\
DFI Motor \\
$\Theta_{M}$ \\
$I_{S}$ \\
$I_{R}$ \\
$n_{p}$ \\
$n_{S}$ \\
$P_{M}$ \\
$P_{M}$ \\
$P_{R}$ \\
\hline$P_{R}$
\end{tabular}

Commercial off-the-shelf Doubly-Fed Induction Machine Doubly-Fed Induction Motor rotor angle, radians stator current phasor, Amps peak rotor current phasor, Amps peak number of pole pairs synchronous speed, rev. per minute mechanical rotor power, Watts per-unit mechanical rotor power electrical rotor power, Watts per-unit rotor power

Nomenclature
\[ \begin{array}{ll}P_{S} & \text { stator power, Watts } \\ P_{S} & \text { per-unit stator power } \\ Q_{R} & \text { rotor reactive power, VAR } \\ Q_{S} & \text { stator reactive power, VAR } \\ \text { RSC } & \text { rotor side converter } \\ S & \text { per-unit slip } \\ V_{R} & \text { rotor voltage phasor, Volts peak } \\ V_{S} & \text { stator voltage phasor, Volts peak } \\ \omega_{M} & \text { rotor speed, radians per second } \\ \omega_{S} & \text { synchronous electrical angular } \\ & \text { frequency, radians per second }\end{array} \]

${ }^{1}$ AST, Power Management and Distribution Branch, david.j.sadey@nasa.gov.

${ }^{2}$ Professor, Electrical and Computer Engineering, bodson@eng.utah.edu, AIAA Associate Fellow.

3 AST, Power Management and Distribution Branch, jeffrey.t.csank@nasa.gov, AIAA Sr. Member.

${ }^{4}$ AST, Diagnostics \& Electromagnetics Branch, keith.r.hunker@nasa.gov,

${ }^{5}$ AST, Space Power and Propulsion Test Engineering Branch, casey.j.theman@nasa.gov,

${ }^{6}$ AST, Power Management and Distribution Branch, linda.m.taylor@nasa.gov. 


\section{Introduction}

$\mathrm{T}$

HE NASA Aeronautics Research Mission Directorate (ARMD), and the aeronautics industry as a whole, is constantly being challenged to achieve reductions in noise, emissions, and fuel burn over today's current aircraft ${ }^{1}$. One of the possible paths forward focuses on partial to complete electrification of the aircraft, depending on size and mission duration. The current approach within NASA ARMD towards further electrification of aircraft has focused on a primarily DC based transmission system ${ }^{2}$, as shown in Fig. 1. This system relies on multiple power conversion stages to transmit the AC power extracted off the turbine driven generator(s) to the AC motor(s) driving the propulsor fan(s). The power must be converted from AC to DC and then back to AC, which requires two stages of full power rated converters; these converters have a large negative impact on the total system weight and efficiency. To overcome this negative impact, the NASA Convergent Aeronautics Solutions (CAS) High Voltage Hybrid Electric Propulsion (HVHEP) task has proposed a primarily AC system, which adopts the use of doubly-fed induction machines (DFIMs), as shown in Fig. 2. This AC system allows for the fully rated power converters of the DC system to be replaced with converters a fraction of the size. These AC converters are only required on the rotors of the DFIMs, resulting in overall weight and efficiency savings. At the same time, the use of DFIMs, as opposed to synchronous machines, enables operation with an electrical frequency which is largely decoupled from the speed of the generator(s) and motor(s). This paper will present a short overview of this system (Section II), describe its operational characteristics and advantages (Section III), then present simulation (Section IV) and hardware results (Section V) based on the independent operation of the downstream propulsor motors.

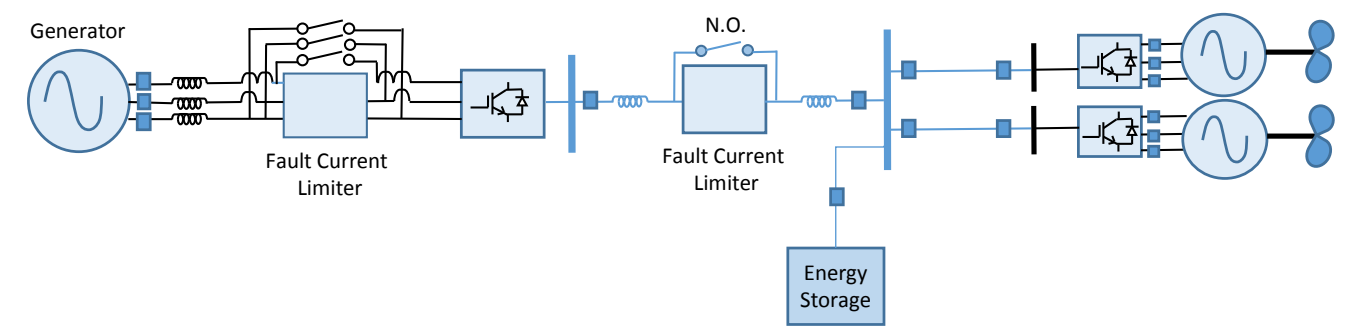

Figure 1. Simplified Baseline DC Power Architecture²

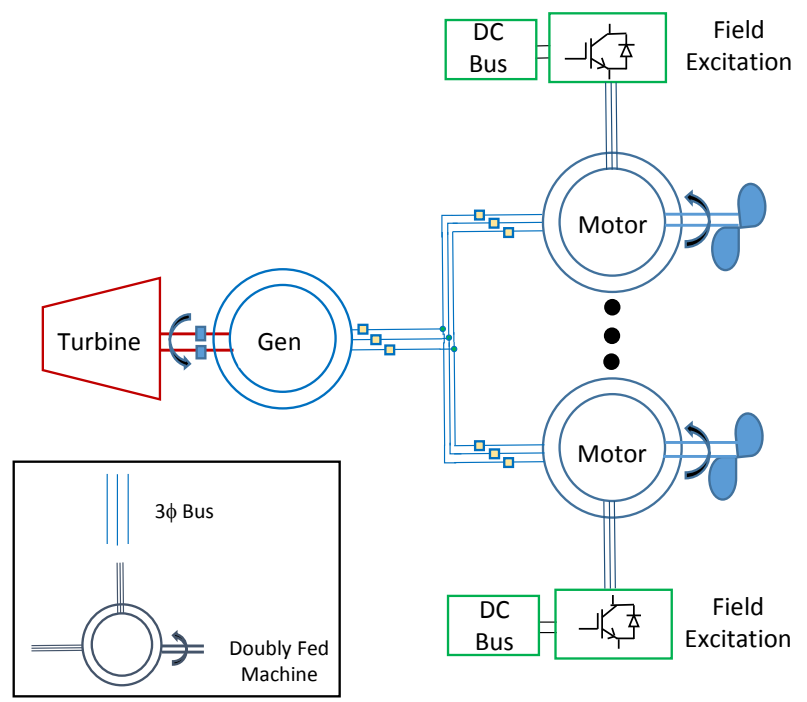

Figure 2. DFIM Based AC Power Architecture 


\section{System Description}

In the proposed AC system, which was originally described in Ref. $3^{*}$ and as seen in Fig. 2, a gas turbine engine acts as a prime mover to an AC generator. The generator then converts that mechanical power to three-phase electric power on its stator. Through the unique nature of the doubly-fed induction motor (DFI Motor), the stator of the generator is directly connected to the stator of the individual motors via a three phase transmission and distribution bus. The DFI motors, which will be described in detail in Section III, are then independently controlled through the use of a rotor side converter (RSC) to drive the propulsors of the aircraft. This system allows for individual control of the fans such that they can operate in concurrence with one another, or differentially.

\section{Doubly-Fed Induction Motors}

The DFIM is a unique machine which has historically been used in wind turbine ${ }^{4}$ applications as a generator, but has uses as a motor as well. This machine has both stator and rotor windings where power can be actively injected into or extracted from. As previously stated, one advantage of the DFI Motor is that it can be designed and exploited in such a way that the power electronics necessary to control the motor are relegated to the low power rotor windings, thus reducing the required size of the power converter itself. In the configuration studied, the stator is directly coupled to a three-phase electric power source (electric grid), while the rotor uses a low-power, partially-rated power converter to achieve variable speed operation of the machine. This section will describe the electric and mechanical theory relative to the machine, how the voltage and power of the RSC vary as a function of slip, and how the machine is controlled.

\section{A. Doubly-Fed Induction Motor Theory}

Figure 3 shows the structure of a DFI Motor. On the left is a side view of the motor and on the right is a crosssection of the motor, showing three-phase stator windings and three-phase rotor windings (in a simplified representation). The voltages applied to the stator windings are labelled $v_{a, S}, v_{b, S}$, and $v_{c, S}$, while the voltages applied to the rotor are labelled $v_{a, R}, v_{b, R}$, and $v_{c, R}$. The rotor voltages are applied through slip rings, as shown to the left. The angle of the rotor winding $a, R$ with respect to the stator winding $a, S$ defines the rotor angular position, denoted $\theta_{M}$, while the angular velocity is denoted $\omega_{M}=d \theta_{M} / d t$.
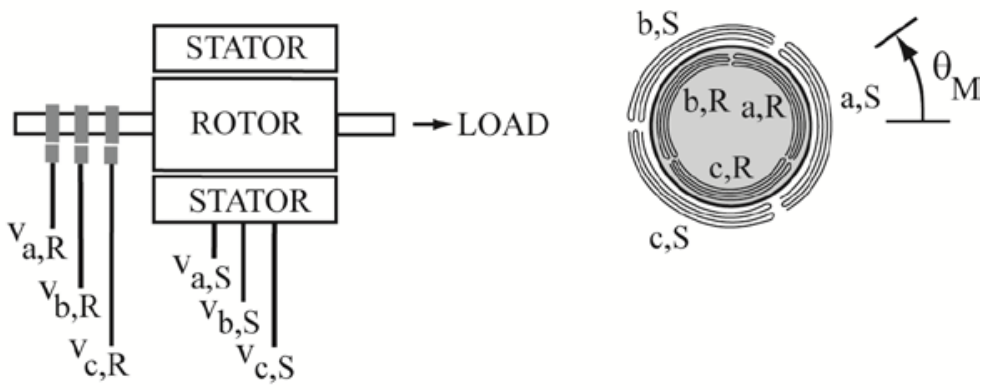

Figure 3. DFI Motor Structure

In steady-state, the stator voltages are sinusoidal variables with frequency $\omega_{s}$, and can represented by a single complex variable $V_{S}$ (typically called a phasor) such that

$$
\begin{gathered}
v_{a, S}=\operatorname{Re}\left(V_{S} e^{j \omega_{S} t}\right) \\
v_{b, S}=\operatorname{Re}\left(V_{S} e^{j \omega_{S} t-j 2 \pi / 3}\right) \\
v_{c, S}=\operatorname{Re}\left(V_{S} e^{j \omega_{S} t+j 2 \pi / 3}\right) .
\end{gathered}
$$

\footnotetext{
${ }^{*}$ It is important to note that the generator may or may not be a doubly-fed machine as described in Ref. 3, and the choice of generator type will depend on the power system architecture and system requirements. Implementing the DFIM as a generator as well may offer additional benefits, but is beyond the scope of this paper.
} 
The total active $\left(P_{S}\right)$ and reactive $\left(Q_{S}\right)$ power absorbed by the stator windings can be expressed as:

$$
P_{S}+j Q_{S}=\frac{3}{2} V_{S} I_{S}^{*}
$$

where $I_{S}^{*}$ is the complex conjugate of the phasor for the stator current. Similarly, the rotor voltages are sinusoidal variables with frequency $s \omega_{S}$, where $s$ is the per-unit slip defined as

$$
\mathrm{s}=1-\frac{n_{P} \omega_{M}}{\omega_{S}}
$$

and $n_{P}$ is the number of pole pairs of the motor ( $n_{P}$ is equal to 1 on Fig. 1$)$. Note that the rotor electrical frequency, $s \omega_{S}$, can be negative, which corresponds to a phasor voltage rotating in the counter-clockwise direction, i.e., threephase rotor voltages in reverse or backward sequence. Defining rotor voltage $\left(V_{R}\right)$ and current $\left(I_{R}\right)$ phasors, the total active and reactive powers absorbed by the rotor are equal to.

$$
P_{R}+j Q_{R}=\frac{3}{2} V_{R} I_{R}^{*}
$$

Neglecting losses in the motor, the mechanical power of the motor is a function of the electrical power supplied to the stator and rotor windings:

$$
P_{M}=\tau \omega_{M}=P_{S}+P_{R}
$$

where $\tau$ is the torque and $\tau \omega_{M}$ is the mechanical power produced by the motor. It is also possible for electrical power to be absorbed by the stator windings and produced by the rotor windings (when $P_{R}<0$ ). An interesting property of the DFI Motor is that it can operate in sub- or super-synchronous modes relative to the grid frequency. This means that while a conventional synchronous machine may operate at only one speed per given stator frequency (called synchronous speed), the DFI Motor has the ability to operate below, at, or above this synchronous speed. In addition, the distribution of power is solely determined by the relative speed of the motor compared to the frequency of the stator input. Specifically, still neglecting losses, it turns out that

$$
\begin{gathered}
P_{S}=\frac{\omega_{S}}{n_{P} \omega_{M}} P_{M} \\
P_{R}=\frac{n_{P} \omega_{M}-\omega_{S}}{\omega_{S}} P_{S}=\frac{n_{P} \omega_{M}-\omega_{S}}{n_{P} \omega_{M}} P_{M} .
\end{gathered}
$$

Therefore, for positive torque and speed, $P_{S}>0$ and $P_{R}>0$ for $n_{P} \omega_{M}>\omega_{S}$ (the super-synchronous case with $s<0$ ) while $P_{S}>0$ and $P_{R}<0$ for $n_{P} \omega_{M}<\omega_{S}$ (the sub-synchronous case with $s>0$ ).

\section{B. DFI Motor Converter Characteristics for Fan Loads}

The converter for the DFI Motor, which is sometimes referred to as the RSC, is typically sized with regard to the operating characteristics of the machine along with the torque-speed (and therefore power) characteristics of the load. While there are numerous ratings and design criteria for the RSC to operate properly according to the system specification, this section focuses specifically on how the voltage and power characteristics of the RSC are derived for fan loads.

The voltage requirement of the RSC is directly proportional to the speed range of the rotor. At standstill, the induced voltage at the terminals of the rotor is at maximum. As the rotor speed increases, the rotor voltage then linearly decreases from its maximum value to zero at synchronous speed ${ }^{5}$. With further increasing speed, the rotor voltage linearly increases back to its open circuit voltage at $200 \%$ rated speed. This voltage-speed characteristic is shown in Fig. 4. 
The voltage-speed characteristic of the DFI Motor may be advantageous in applications where aircraft propulsors require only a limited speed range to operate. For example, if the required speed range is 15\% about synchronous speed, the voltage requirement of the RSC would only be 0.15 per-unit of the open circuit rotor voltage. This would in-turn force a requirement for the stator bus to be a variable frequency bus, or for a mechanical or electrical starting mechanism for the machine (e.g. crowbar circuit), but those requirements are beyond the scope of this paper.

As mentioned previously, the power characteristic of the RSC is related to the torque-speed characteristics of the fan load, along with the characteristics of the DFI Motor itself. References 5 and 6 show the torque required to drive a fan load is actually proportional to the speed squared, which results in Eqs. (10), (11), and (12) describing the DFI Motor, stator, and rotor powers on a per-unit basis, respectively. The regenerated RSC power, $\overline{P_{C O N V}}$, in per-unit of the rated machine power, is given by Eq. (12) as well.

$$
\begin{gathered}
\overline{P_{M}}=\overline{\omega_{R}^{3}} \\
\overline{P_{S}}=\overline{\omega_{R}^{2}}, \\
\overline{P_{R}}=-\overline{P_{C O N V}}=\overline{\omega_{R}^{3}}-\overline{\omega_{R}^{2}}
\end{gathered}
$$

The relationship between the stator, rotor, and mechanical power as described by Eqs. (10-12) was shown by Ref. 5 for sub-synchronous operation. This plot is extended to super-synchronous operation (15\% over synchronous speed) in Fig. 5. The dashed line shows the mechanical power $\left(\overline{P_{M}}\right)$, the dotted line shows the regenerated rotor power $\left(\overline{P_{\text {CONV }}}\right)$, and the solid line shows the stator electrical power $\left(\overline{P_{S}}\right)$. It is important to recognize that if zero to full speed operation were required for the machine, along with self-starting, the steady-state power processed by the RSC would only need to be approximately $15 \%$ of the rated power of the machine. In other words, because the power absorbed by a fan load is proportional to the cube of the speed, the range of speed for which a 15\% RSC is applicable covers the whole sub-synchronous speed range. Conversely, for super-synchronous speeds, the range is shortened, but the machine can still operate up to $12 \%$ above rated speed. These operating points are identified in Fig. 5 accordingly.

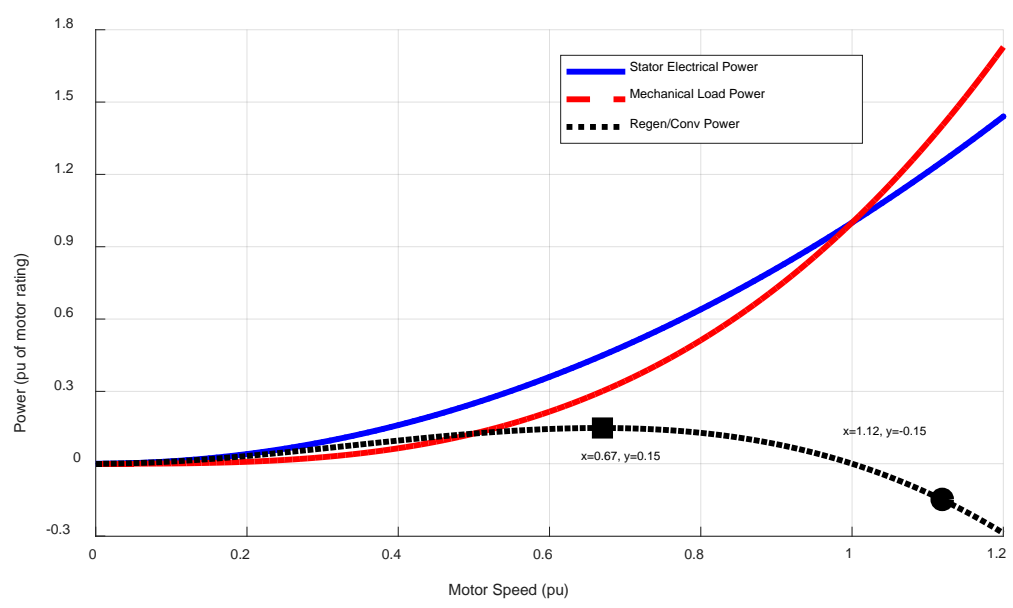

Figure 5. Power Curves DFI Motor 
As a summary, the voltage requirement of the RSC is defined by the speed range and open circuit voltage of the rotor (with the stator fully excited). The total power processed is defined by Eq. (12). Ignoring accelerating power, this results in a reduction of at least $85 \%$ in power converted by the converters as compared to the DC baseline architecture, with an increased speed range of $12 \%$ without the requirement for field weakening over the baseline as well. Additional speed capability is possible, but depends on the operational characteristics and requirements of the system.

\section{DFI Motor Control}

Figure 6 shows a block diagram of a control algorithm for the DFI Motor. The stator windings are connected to a three-phase grid through a relay. In a turboelectric application, the grid is provided by a generator, possibly of a doubly-fed induction type. The torque control block serves both to synchronize the machine to the grid before connection and to control the torque of the motor when connected. The vector of rotor voltages $v_{R}=\left(v_{a, R} v_{b, R} v_{c, R}\right)^{\mathrm{T}}$ is computed to provide a torque equal to the command $\tau_{C O M}$ while absorbing zero stator reactive power $\left(Q_{s}=0\right)$. The computation is based on measurements of the rotor position $\theta_{M}$, of the rotor velocity $\omega_{M}$, and of the stator voltage vector $v_{S}=\left(v_{a, S} v_{b, S} v_{c, S}\right)^{\mathrm{T}}$. Before connection to the grid, the grid voltage vector $v_{G}=\left(v_{a, G} v_{b, G} v_{c, G}\right)^{\mathrm{T}}$ is also measured, and the rotor voltage vector is computed to ensure that $v_{S}=v_{G}$. This situation corresponds to a zero torque and zero reactive power, implying zero stator currents and, therefore, a possible connection to the grid with zero transients. When the voltages are equal, the operator triggers the connect variable, which closes the relay between the grid and the DFI Motor. The connection can also be performed automatically.

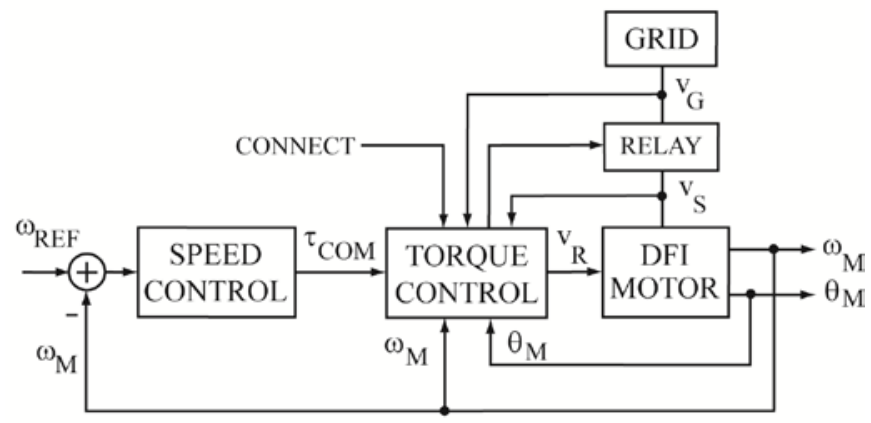

Figure 6. Speed Control Algorithm

The inner torque control algorithm is augmented by an outer loop for speed control that ensures the tracking of a reference command $\omega_{R E F}$ by the speed $\omega_{M}$. The speed control algorithm is a conventional proportional-integral control system with anti-windup protection. The torque command is limited to ensure that the predicted rotor currents stay within their limits.

In Fig. 6, the rotor voltages are computed to produce a given torque with zero absorbed stator reactive power (all reactive power required by the magnetizing current is provided by the RSC to the rotor). However, an extension of the algorithm could enable the control of the reactive power using a second outer loop with reference $Q_{R E F}$ and a feedback of the stator reactive power based on measurements of the stator and rotor currents (not shown in Fig. 6).

\section{Simulation Results}

To demonstrate and evaluate the general performance of the aforementioned control structure, a simple single string model of the DFI Motor was developed, as shown in Fig. 7. The DFI Motor is coupled to a permanent magnet DC (PMDC) machine which acts as a load, with the characteristics of the machines listed in Tables 1 and 2. The characteristics were taken from a mix of nameplate and test data from commercial off-the-shelf (COTS) hardware that were procured for hardware testing. Loading in the simulation was performed with a constant maximum torque load, as the ability to implement a dynamic fan load torquespeed characteristic was not possible with the hardware used

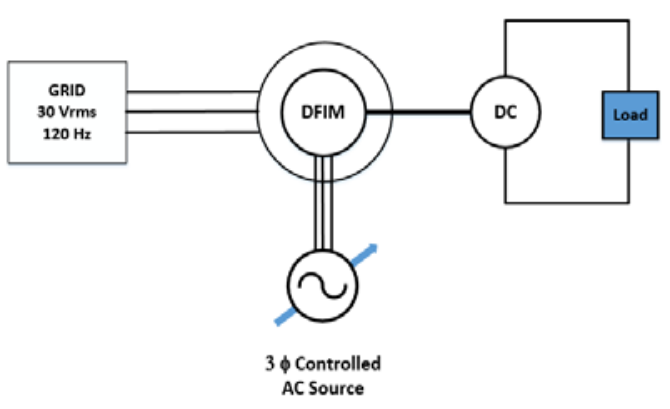

Figure 7. Single String DFI Motor Test Setup 
in Section V. The control algorithm was tuned for both the speed control and reactive power control loops, in which acceptable performance was observed. The results of the simulation are shown in Fig. 8, in which the machine is shown to have synchronized, self-started, transitioned through sub-synchronous, synchronous, and super-synchronous modes, and automatically controlled its reactive power to obtain unity power factor operation at the stator.

Table 1. DFI Motor Characteristics. All Electrical Parameters are Referred to the Stator Side**

\begin{tabular}{lcc}
\hline Parameter & Value & Units \\
\hline Rated Power & 250 & $\mathrm{~W}$ \\
Rated Stator Voltage & 30 & $\mathrm{~V}$ \\
Rated Frequency & 120 & $\mathrm{~Hz}$ \\
Synchronous Speed & 3600 & $\mathrm{RPM}$ \\
Pole Pairs & 2 & - \\
Stator Inductance Ls** & 2.5 & $\mathrm{mH}$ \\
Stator Resistance Rs** & 0.6 & $\Omega$ \\
Mutual Inductance Lm** & 6.6 & $\mathrm{mH}$ \\
Rotor Inductance** & 0.24 & $\mathrm{mH}$ \\
Rotor Resistance Rs** & 1.21 & $\Omega$ \\
Stator Connection & Star & - \\
Rotor Connection & Delta & - \\
\hline
\end{tabular}

Table 2. DC Machine Characteristics

\begin{tabular}{lcc}
\hline Parameter & Value & Units \\
\hline Rated Power & 250 & $\mathrm{~W}$ \\
Rated Voltage & 42 & $\mathrm{~V}$ \\
Rated Speed & 4000 & $\mathrm{RPM}$ \\
Pole Pairs & 1 & - \\
Armature Resistance & 0.52 & $\Omega$ \\
Armature Inductance & 2.7 & $\mathrm{mH}$ \\
\hline
\end{tabular}
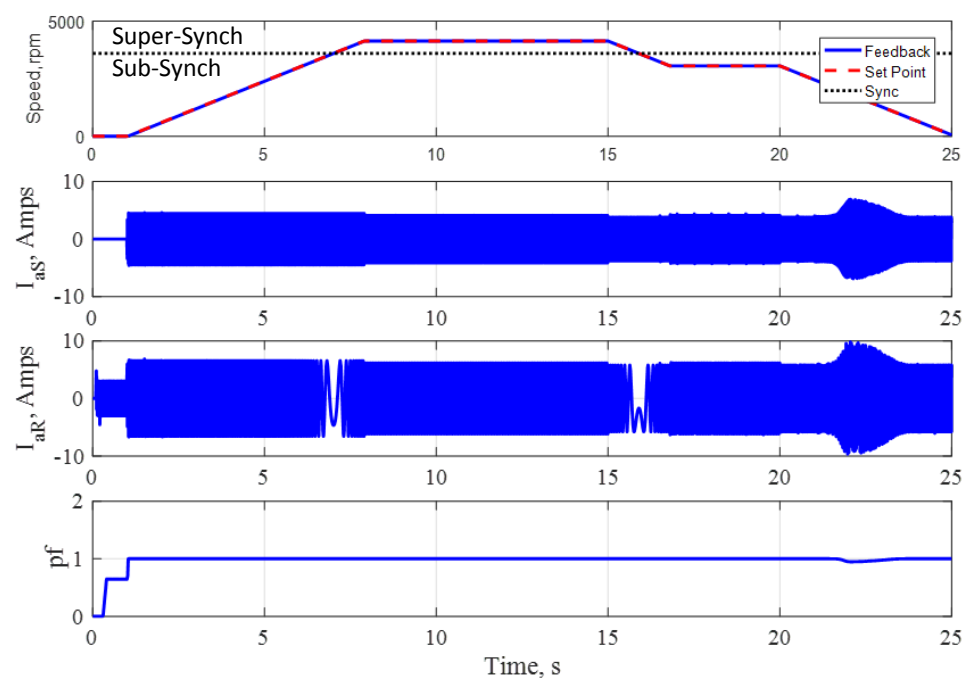

Figure 8. Simulation Results for Single String DFI Motor Test

\section{Hardware Results}

To evaluate the proposed system and its control, a low power test bed was constructed using COTS hardware. The test bed power hardware included three fractional horsepower DFI Motors, three 42V, three-phase inverters, three permanent magnet DC machines (previously described) to act as dynamometers, and a three-phase power supply. The test bed configuration is shown in Fig. 9 and the power hardware shown in Fig. 10. The test bed motors are configured in such a way to represent a distributed propulsor based aircraft. The system configuration was selected to demonstrate the ability for the motors to operate in parallel, both for concurrent and differential operation, and for convenience and cost purposes. It is important to note that during the hardware testing, it was observed that the DFI Motors could not output as much power as specified on the nameplate (only approximately 100W). Furthermore, bandwidth restrictions 
in hardware limited the ability to follow a desired fan-type torque-speed curve dynamically. These restrictions, in addition to slightly differing characteristics across machines, led to the application of a linear torque-speed curve (resistor on the dynamometer) versus the previously discussed fan-load. Despite these limitations, the ability for the machines to synchronize to the main bus, self-start, operate concurrently and differentially, along with follow a theoretical flight profile was demonstrated.

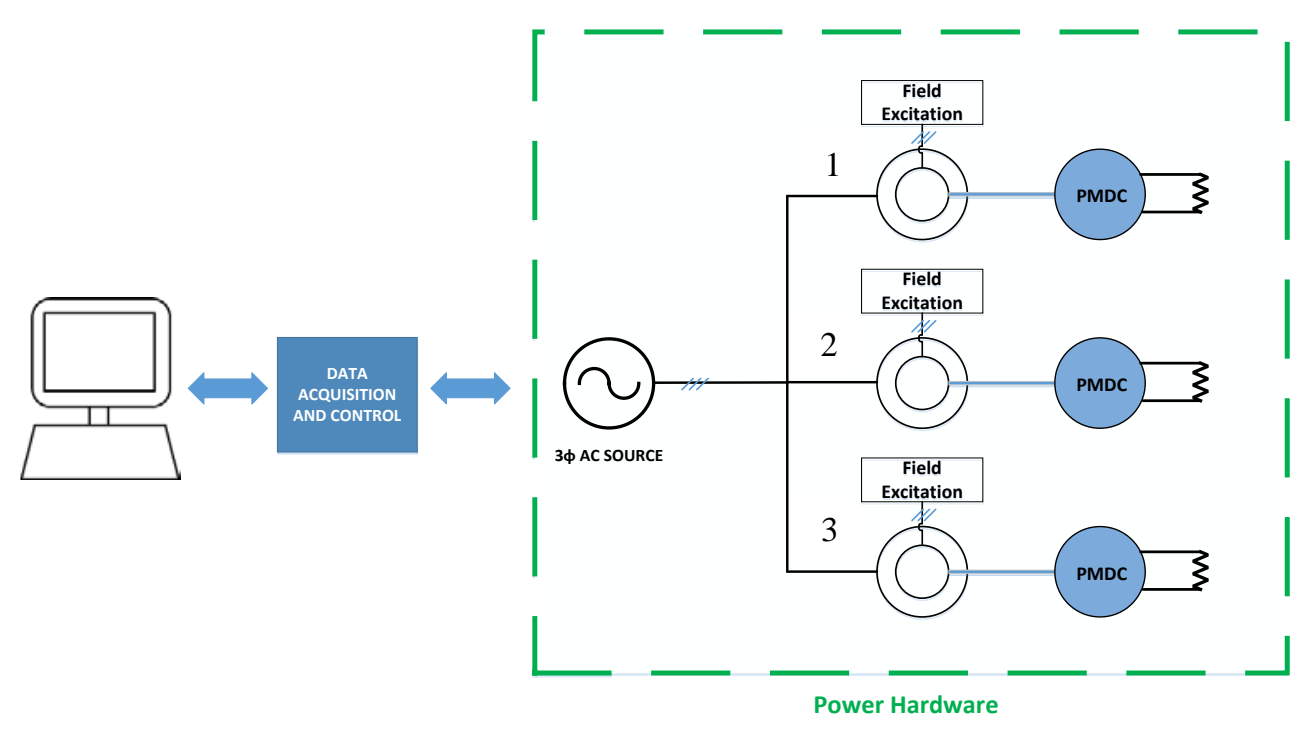

Figure 9. Low Power Test Bed Structure

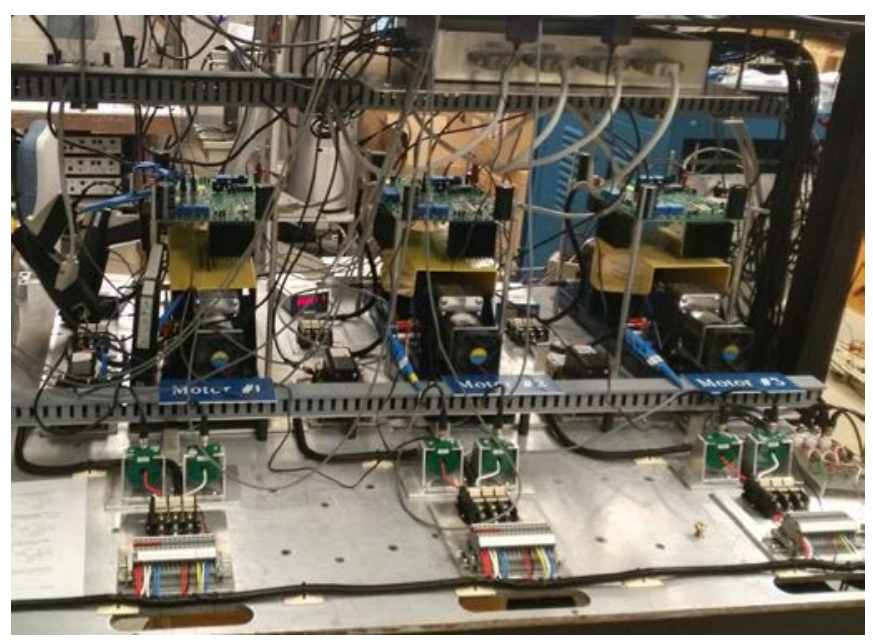

Figure 10: Low Power Test Bed Power Hardware

\section{A. Synchronization}

The ability of the DFI Motors to synchronize to the grid is demonstrated in Figs. 11 and 12, with the Motor 2 synchronization as an example. As described previously, the rotor of each machine is excited in such a way that the stator voltages match the bus voltages in magnitude, fundamental frequency, and phase. Once these parameters match, the main contactors are closed, locking the stators of the machines to the grid and enabling closed-loop speed control. In the test bed demonstration, this process was performed manually using filtered signals. For this reason, when the contactor for Motor 2 was closed at approximately 3.445 seconds, a slight transient was encountered, as shown in the figures below. The transient is eliminated within one second, as one can see the shaft of Motor 2 returning to standstill. It is expected that an automated synchronization algorithm would reduce the current and velocity transients further. 

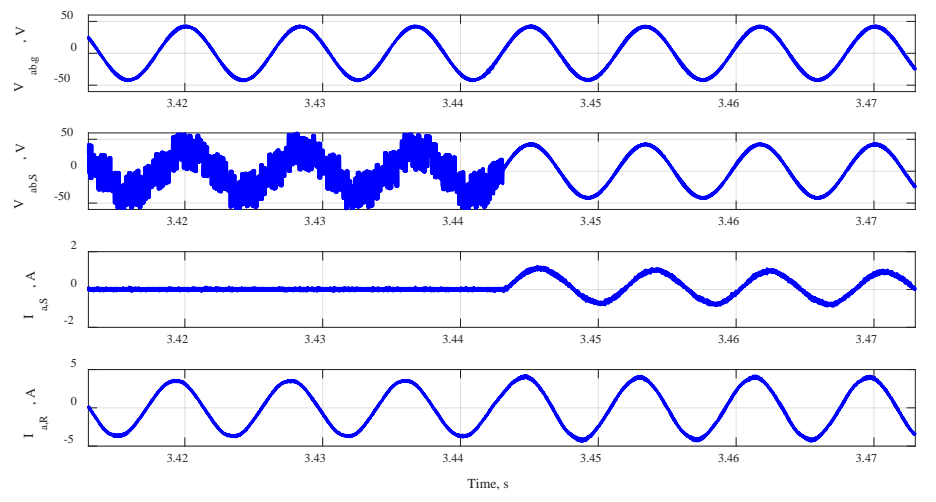

Figure 11. Grid Voltage $\left(V_{a b, g}\right)$ and Motor 2 Stator Voltage $\left(V_{a b, s}\right)$, Stator Current $\left(I_{a, s}\right)$, and Rotor Current $\left(\mathbf{I}_{\mathbf{a}, \mathrm{R}}\right)$

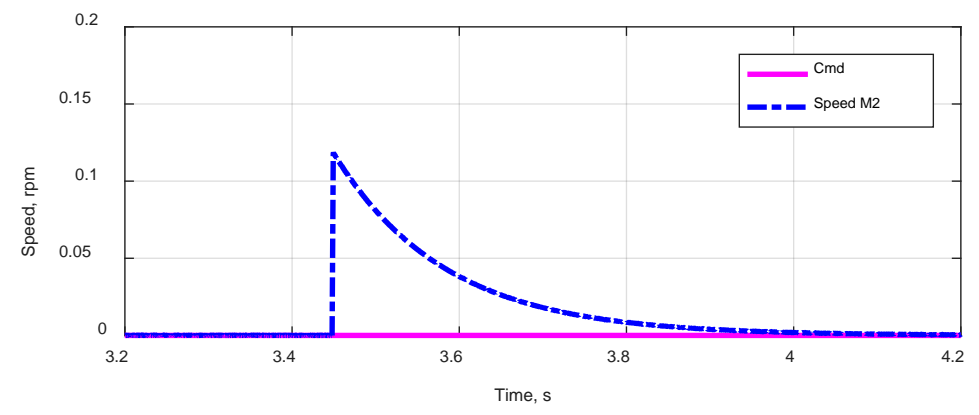

Figure 12. Motor 2 Speed During Synchronization

\section{B. Startup}

The startup speed curves of the three motors from standstill to synchronous speed at 3600 RPM is shown in Fig. 13, along with the averaged power factor over that time period. Each of the three motors demonstrated balanced operation during the startup transients, and tracked the reference command well. The power factor signal was computed based on filtered signals, and averaged over a number of cycles. The average power factor (not instantaneous) was shown to achieve close to unity power factor operation. The RMS line-to-line voltage and stator and rotor currents are shown in Fig. 14 for additional information.
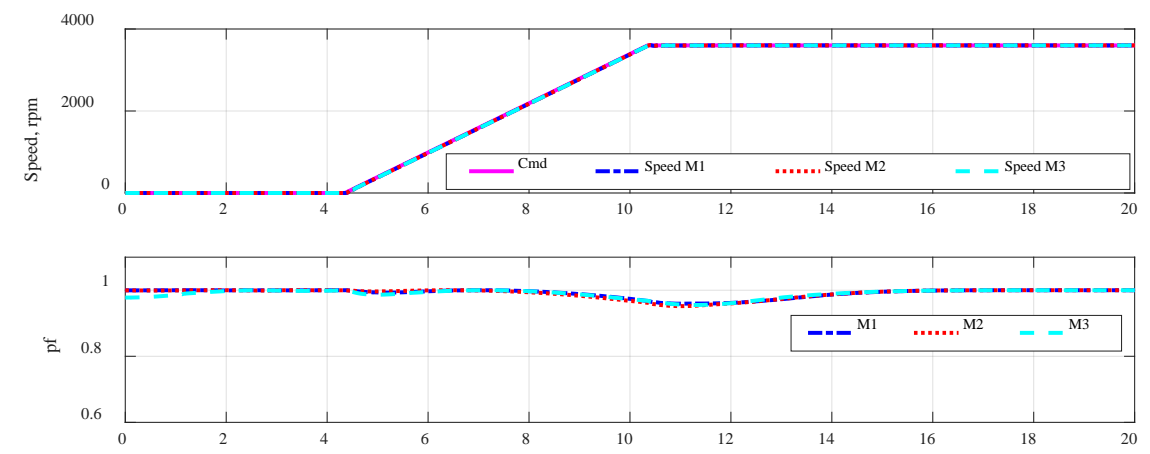

Figure 13. Speed Reference Tracking (Top) and Unity Stator Power Factor Control (Bottom) During Startup 

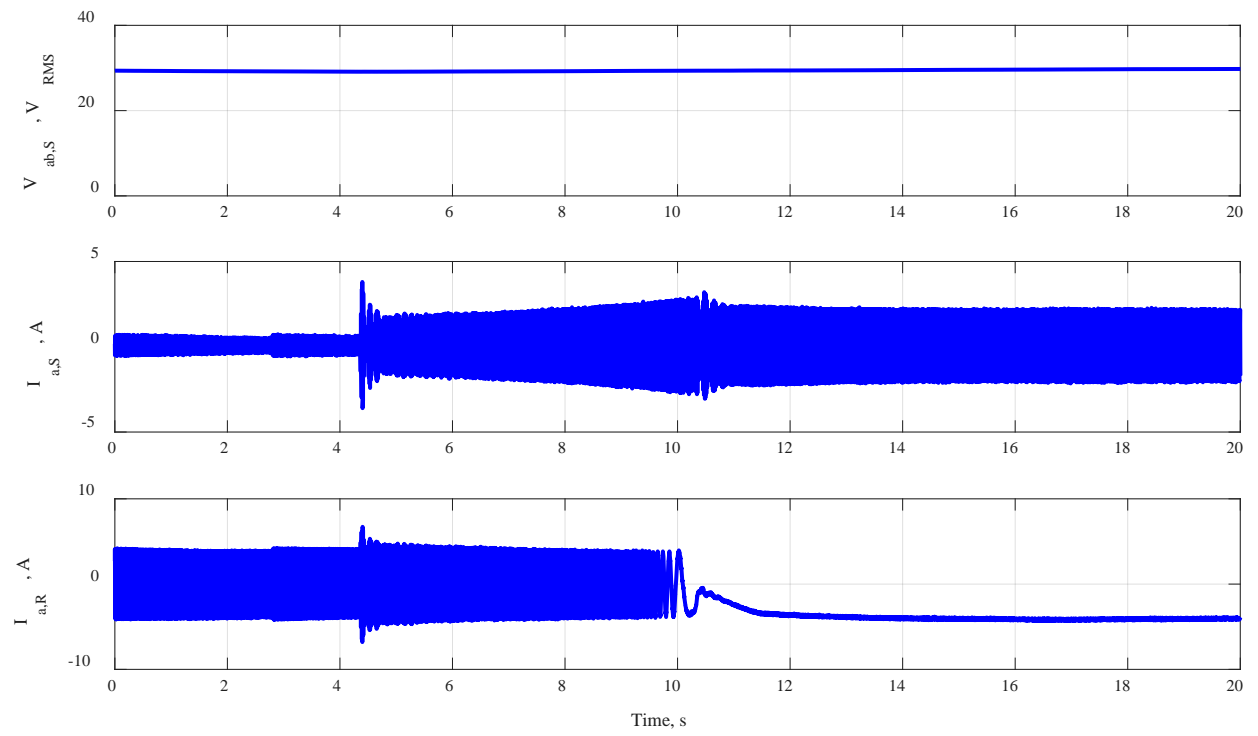

Figure 14. Motor 2 Line to Line RMS Stator Voltage (Top), Phase A Stator Current (Middle), and Phase A Rotor Current (Bottom)

\section{Differential Operation}

The ability for the propulsors to operate simultaneously at different speeds (differential operation), along with transitioning back and forth between differential and concurrent operation is assumed to be necessary for distributed propulsion based aircraft. This ability, in addition to the averaged power factors of the machines over the noted time, was demonstrated as shown in Fig. 15. As one can see, independent from what is occurring with the other machines, the motors track their individual set-points In addition, the stator line-to-line RMS voltage, and the stator and rotor currents of Motor 2 are highlighted in Fig. 16.
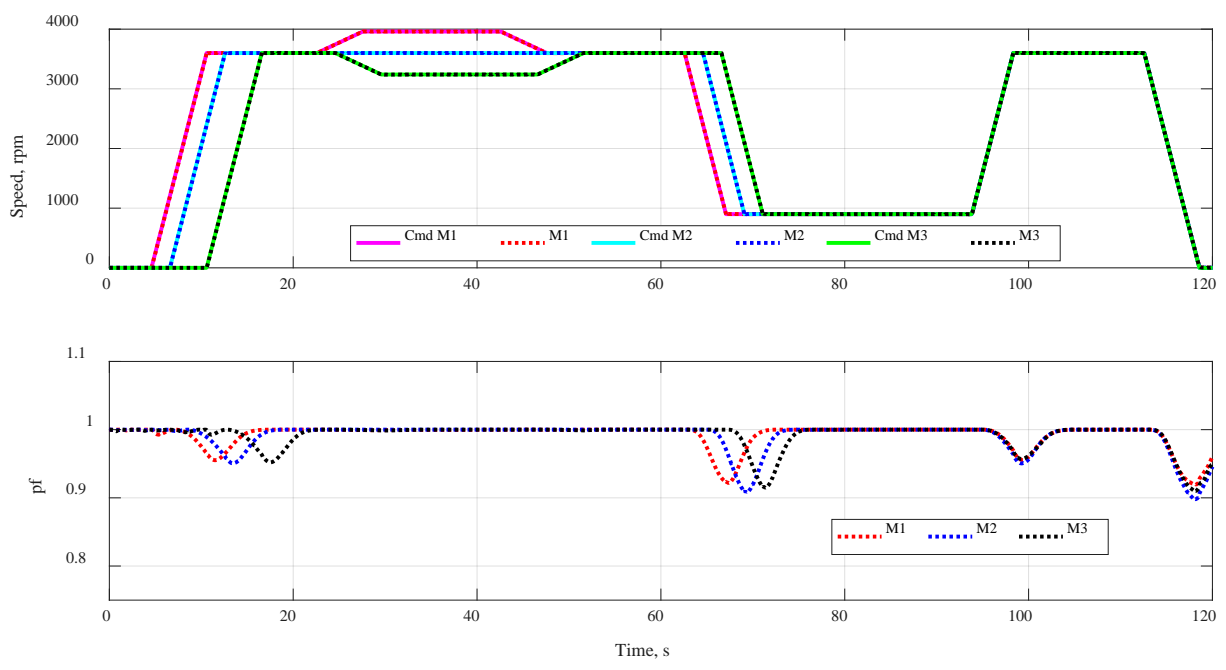

Figure 15. Speed Command Set-point Tracking for All Three Motors Demonstrating Differential Speed Operation (Top), and Average Stator Power Factor for All Three Motors (Bottom) 

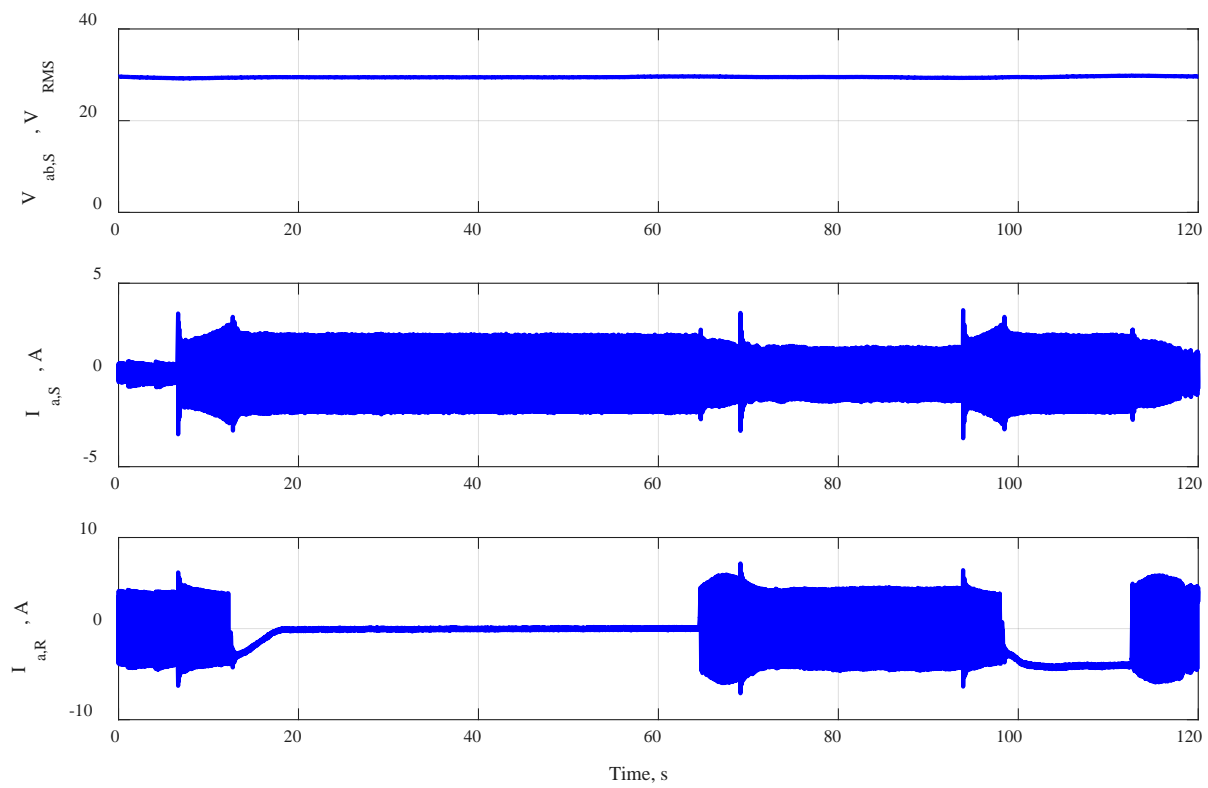

Figure 16. Motor 2 Differential Speed Tracking Voltage and Current Data

\section{Flight Profile Set-point Tracking}

The ability for the propulsors to follow a theoretical flight profile with characteristics shown in Fig. 17, is shown in Fig. 18. The motors track the speed-profile with no deviation from the set-point, and near average unity power factor at the stator is demonstrated over the duration of the flight profile. The Motor 2 voltage and current data is plotted in Fig. 19 as done previously as well.
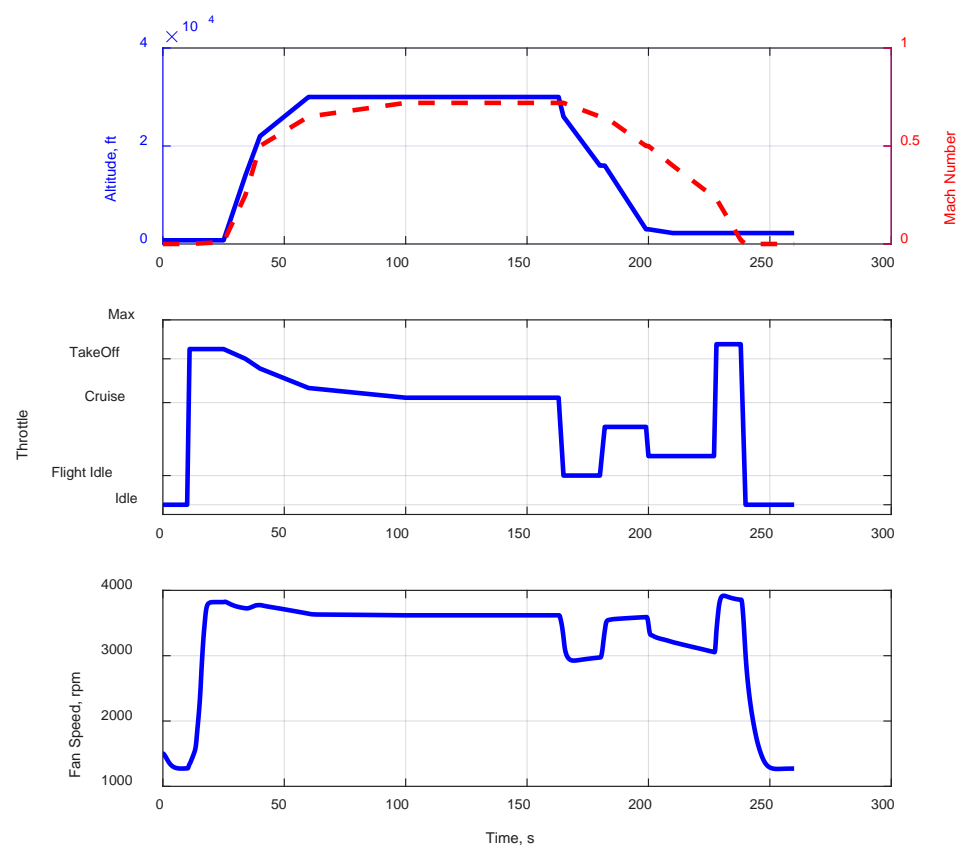

Figure 17. Parallel Motor Flight Profile 

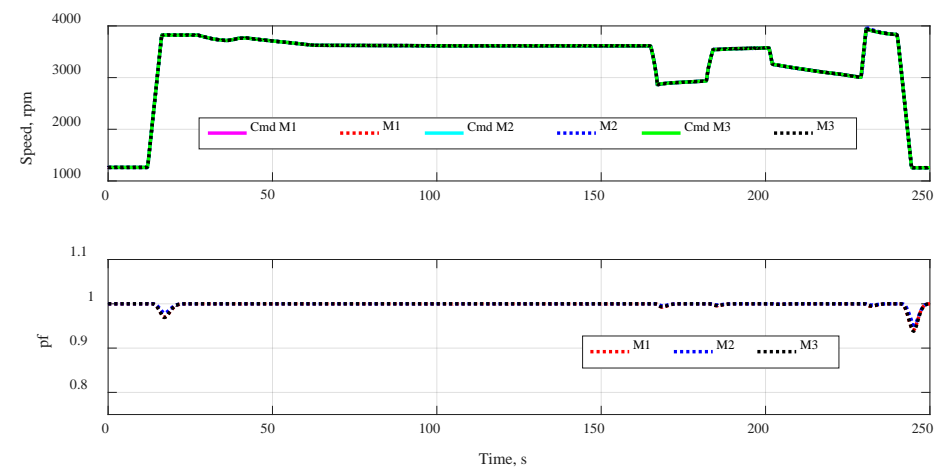

Figure 18. Flight Profile Speed and Stator Power Factor Tracking Capability, with a 30VLL, 120 Hz Bus.
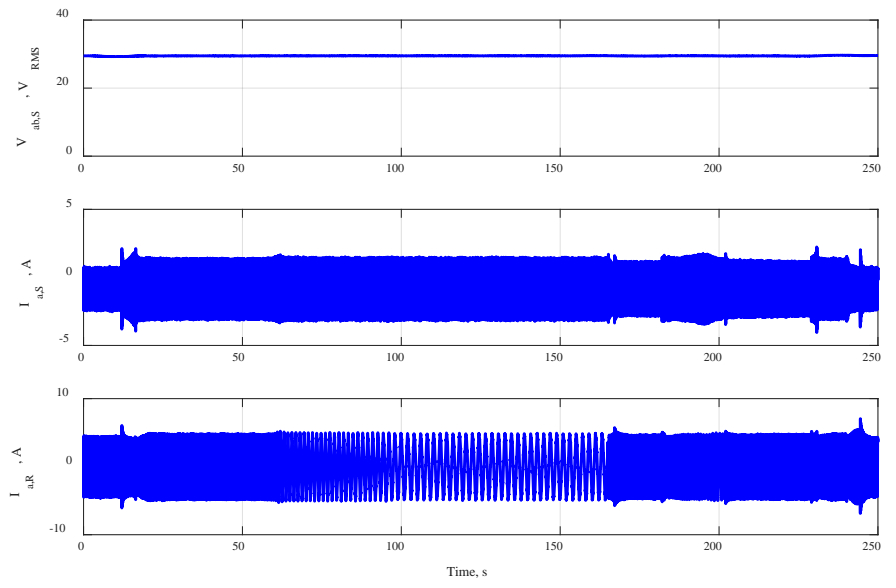

Figure 19. Motor 2 Flight Profile Voltage and Current Data

\section{Conclusion}

The general operating characteristics and control of the DFI Motor and its inverter were described and demonstrated in both simulation and experiments. This operation included the DFI Motor's ability to synchronize itself to the grid, self-start (with the properly sized power electronics), operate over a wide speed range both synchronously and differentially with other DFI Motors off of the same bus, and operate with its average power factor at unity during steady-state operation. These characteristics are highly desirable for flight application, allowing similar performance to that of a series driven synchronous or induction machine.

While a DFI Motor based AC power system has been shown to have several positive qualities, there is still much study and work to be done. In the near future work, demonstration of a fully DFIM based system with the DFIM as the generator and the motor(s) will be reported utilizing the low power test bed. In addition, more accurate loading models are necessary to represent in-flight fan load dynamics and the respective sizing of the RSC for such a load, since the test bed bandwidth limitations only allowed for a linear torque-speed curve to be implemented. After that, studies need to be performed regarding the performance of the AC system in relation to the stiffness of the AC bus, DFIM scaling to high power and possibly high speed operation, brushless concepts, and so on. These efforts will all lead into potential medium (several hundred $\mathrm{kW}$ ) and/or high power tests (MW) for future aircraft electric propulsion.

\section{Acknowledgments}

The authors would like to thank the NASA CAS project and Ray Beach in support of this effort, along with Jim Dolce, Tom Balogas, David Hausser, and George Horning of the CAS HVHEP activity for their assistance in the construction of the low power test bed. 


\section{References}

1 “NASA Aeronautics Strategic Implementation Plan 2017 Update,” National Aeronautics and Space Administration, 2017, https://www.nasa.gov/sites/default/files/atoms/files/sip-2017-03-23-17-high.pdf [retrieved 9 May 2017].

${ }^{2}$ Armstrong, M.J., et al., RTAPS “Architecture, Voltage, and Components for a Turboelectric Distributed Propulsion Electric Grid,” NASA CR-2015-218440, NASA CR, July 2015.

${ }^{3}$ Sadey, D.J., Taylor, L.M., and Beach, R.F., "Proposal and Development of a High Voltage Variable Frequency Alternating Current Power System for Hybrid Electric Aircraft", AIAA 2016-4928, 14th International Energy Conversion Engineering Conference, Salt Lake City, UT, July 25-27, 2016.

${ }^{4}$ Muller, S., Deicke, M., and De Doncker, R.W., "Doubly fed induction generator systems for wind turbines", IEEE Ind. Appl. Mag., vol. 8, no. 3, pp. 26-33, May/Jun. 2002.

${ }^{5}$ Dick, B., "New Technology for Speed Control of Wound Rotor Motors," 1635721, IEEE Cement Industry Technical Conference, 2006.

${ }^{6}$ Yuan, X., Chai, J., and Li, Y., “A Converter-Based Starting Method and Speed Control of Doubly Fed Induction Machine With Centrifugal Loads,” IEEE Transactions on Industry Applications, vol. 47, no. 3, pp. 1409-1418, May-June 2011. 